\title{
留ESE
}

Revista Eletrônica dos Pós-Graduandos em Sociologia Política da UFSC

Vol. 5. n. 1 (1) agosto-dezembro/2008

ISSN 1806-5023

\section{Reforma Sindical no Governo Lula: restou algo do consenso?}

\section{Frank Ferreira dos Santos ${ }^{1}$}

RESUMO: O presente artigo analisa as transformações almejadas pelo governo de Luiz Inácio Lula da Silva, no que concerne à estrutura sindical, inicialmente através da Proposta de Emenda à Constituição (PEC) 369/05, principal legado do Fórum Nacional do Trabalho, passando pelas alternativas a esse texto. Com o auxílio de reportagens, leituras de Projetos de Lei, Emendas Complementares e Medidas Provisórias, argumento que as principais transformações propostas pela PEC foram abandonadas, sobretudo pela impossibilidade de um consenso entre governo, trabalhadores $\mathrm{e}$ empresários. E que as alternativas propostas convergem para a manutenção da estrutura sindical consagrada pela Constituição Federal de 1988, salvo uma peculiaridade: incluir as centrais sindicais nesta estrutura, no que traduzir-se-ia em vitória do "cupulismo" sindical.

PALAVRAS-CHAVE: Sindicalismo, Governo Lula, Reforma Sindical, Partido dos Trabalhadores, Fórum Nacional do Trabalho.

ABSTRACT: This paper analyzes the changes aimed by Luiz Inácio Lula da Silva government in regard to the union structure, placing as the main argument that the legal changes were abandoned, mainly due to the impossibility of a consensus among government, workers and entrepreneurs. And that the alternative proposals did not change the union structure, except by one peculiarity: the inclusion of labor unions, translating that into a victory of the union elite.

\section{I - INTRODUÇÃO}

Ainda no ano de 2002, o então candidato Luiz Inácio Lula da Silva sinalizava com o estabelecimento de um novo código mínimo de trabalho e renovação da relação

1 Bacharel em Ciências Sociais pela Universidade Federal Fluminense (UFF). Mestrando em Sociologia Política pela Universidade Federal de Santa Catarina (UFSC). 


\section{管ESE}

Revista Eletrônica dos Pós-Graduandos em Sociologia Política da UFSC

Vol. 5. n. 1 (1) agosto-dezembro/2008

ISSN 1806-5023

tripartite entre governo federal, trabalhadores e empresários. Sua postura era pautada pela busca do consenso, uma vez que os ambientes sindical e empresarial encontravamse titubeantes devido à possibilidade de mudanças na estrutura sindical.

As centrais sindicais não encontravam pontos em comum para construírem uma proposta uniforme de reforma na estrutura sindical que pudesse ser entregue ao governo $^{2}$. Nutriam, contudo, o temor de perder poder frente aos sindicatos, uma vez que a reforma poderia provocar disputas entre as centrais na busca por novos adeptos (Folha Online, 02/06/2004).

Os objetivos da reforma sindical ambicionada pelo governo federal preocupavam também os sindicatos menores, aparentemente fadados ao desaparecimento. Os sindicatos com elevado número de filiados e "auto-sustentáveis", pelo contrário, posicionavam-se favoráveis a pontos como o fim do imposto sindical. Os empresários interpretavam a reforma sindical como propositora de elevação dos trabalhadores a um papel que poderia desequilibrar o status quo vigente, "desgastando" a relação capital-trabalho.

Como caráter introdutório, torna-se relevante salientar a importância da hegemonia política na execução de qualquer diretriz ideológico-institucional. Segundo Gramsci (2000, p. 48),

"O fato da hegemonia pressupõe indubitavelmente que sejam levados em conta os interesses e as tendências dos grupos sobre os quais a hegemonia será

2 A Central Única dos Trabalhadores (CUT) queria que as mudanças fortalecessem os sindicatos; Força Sindical desejava primeiro discutir acerca das reformas tributária e da previdência; Central Geral dos Trabalhadores (CGT) e Central Geral dos Trabalhadores do Brasil (CGTB) almejavam a manutenção do modelo sindical atual; Social Democracia Sindical (SDS) desejava manter unicidade entre os sindicatos e pluralidade nas federações e confederações (Folha Online, 24/11/2002). 


\section{留ESE}

Revista Eletrônica dos Pós-Graduandos em Sociologia Política da UFSC

Vol. 5. n. 1 (1) agosto-dezembro/2008

ISSN 1806-5023

exercida, que se forme um certo equilíbrio de compromisso, isto é, que o grupo dirigente faça sacrifícios de ordem econômico-corporativa; mas também é indubitável que tais sacrifícios e tal compromisso não podem envolver o essencial, dado que, se a hegemonia é ético-política, não pode deixar de ser também econômica, não pode deixar de ter seu fundamento na função decisiva que o grupo dirigente exerce no núcleo decisivo da atividade econômica”.

Gramsci é mais específico no trato da hegemonia quando se refere ao âmbito parlamentar, que é o caso da reforma sindical. No parlamento, a hegemonia tem de ser uma combinação de força e consenso,

"que se equilibram de modo variado, sem que a força suplante em muito o consenso, mas, ao contrário, tentando fazer com que a força pareça apoiada no consenso da maioria, expresso pelos chamados órgãos da opinião pública - jornais e associações -, os quais, por isso, em certas situações, são artificialmente multiplicados" (GRAMSCI, 2000, p. 95).

Para almejar a conquista de hegemonia em relação ao debate travado entre as diversas frações envolvidas na disputa por espaço e influência (como é o caso da esfera sindical), é preciso mais do que disposição e vontade. Torna-se imperativo demonstrar suficiente vigor para organizar os interesses desconexos, trazendo consigo apoio para tal empreitada.

Surpreende então o fato de que um governo fortalecido quando de sua posse e "empenhado" para aprovação desta matéria, tenha soçobrado em seu intuito. O que ocorreu de tão importante a ponto de travar mudanças profundas e efetivas? Que fatores foram relevantes para este governo malograr nas suas intenções, ainda mais levando em 


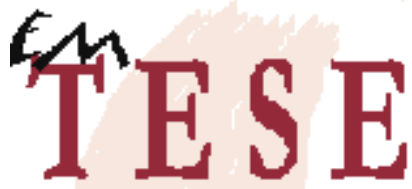

Revista Eletrônica dos Pós-Graduandos em Sociologia Política da UFSC

Vol. 5. n. 1 (1) agosto-dezembro/2008

ISSN 1806-5023

consideração que os quadros comprometidos na esfera estatal com a matéria, no período 2003-2008, eram ligados de alguma forma a sindicatos ou colocavam-se como estudiosos eminentes do tema ${ }^{3}$ ?

São questionamentos como esses que devemos ter em vista, para entendermos por quais motivos a PEC 369/05, fruto de um "consenso" - como a intelligentzia governista sempre fez questão de salientar -, foi destinada a ficar nas gavetas do Congresso Nacional, dando espaço para propostas meramente paliativas. Afinal de contas: o que motivou o ocaso da PEC 369/05? Quais discussões relevantes restaram deste "consenso"? Quem saiu fortalecido"?

\section{II - FÓRUM NACIONAL DO TRABALHO E PEC 369/05}

O início das conversações com os outros atores políticos (empresários e sindicalistas) colocava-se num patamar favorável ao governo federal, influenciado pela vitória acachapante de Lula nas eleições presidenciais de 2002. Em 2003, no primeiro ano de governo, era criado o Fórum Nacional do Trabalho (FNT), que se compunha por representantes do Estado, trabalhadores e empresários em oito grupos temáticos, a saber: organização sindical; negociação coletiva; sistema de composição de conflitos; legislação do trabalho; organização

3 Além de Luiz Inácio Lula da Silva, Ex-presidente do Sindicato dos Metalúrgicos de São Bernardo do Campo (SP), temos, entre outros exemplos, os casos de Vicente Paulo da Silva (Vicentinho), expresidente da CUT nos anos 1990; Maurício Rands, advogado trabalhista, pós-graduado em Direito do Trabalho e Relações Industriais (Università di Bari, Itália, 1990-1991), Doutorado em Política, com tese sobre relações do Trabalho no Brasil (Univ. of Oxford, Inglaterra, 1992-1996); Ricardo Berzoini, exPresidente do Sindicato dos Bancários de São Paulo; Luiz Marinho, ex-presidente da Central Única dos Trabalhadores; Jaques Wagner, Fundador da CUT e ex-presidente do Sindicato dos Trabalhadores da Indústria Petroquímica (Sindiquímica).

4 Matérias concernentes à esfera trabalhista, como discussão sobre a "Super-Receita" e o veto à Emenda 3 , não serão temas de análise neste artigo. 


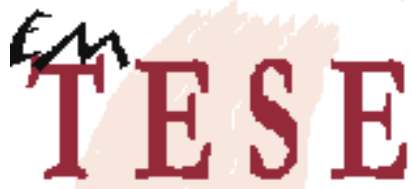

Revista Eletrônica dos Pós-Graduandos em Sociologia Política da UFSC

Vol. 5. n. 1 (1) agosto-dezembro/2008

ISSN 1806-5023

administrativa e judiciária do trabalho; normas administrativas sobre condições de trabalho; qualificação e certificação profissional; e micro e pequenas empresas, autogestão e informalidade.

A criação do Fórum Nacional do Trabalho - que funcionaria como local para análise de propostas visando modificar as estruturas sindical e trabalhista - parecia ser o palco no qual o governo federal tentaria exercer sua autoridade no conflito entre capital e trabalho, a começar pela escolha dos representantes de empresários e trabalhadores no fórum. Esse último ponto torna-se demasiado relevante quando se constata que os membros da estrutura sindical oficial (confederações, federações e sindicatos) foram, na melhor das hipóteses, sub-representados no FNT.

No que concerne uma discussão mais aprofundada acerca da Reforma Sindical, o que resultou do Fórum Nacional do Trabalho foi o "Relatório Final da Reforma Sindical", entregue para apreciação ao Presidente Luiz Inácio Lula da Silva, em abril de 2004. Este relatório seria aproveitado na redação final da Proposta de Emenda à Constituição 369/05.

A PEC 369/05 principia-se tratando da representatividade nas mais variadas gradações sindicais. A agregação de trabalhadores e de empregados definir-se-ia pelos critérios de setor econômico e/ou ramo de atividade, de acordo com o definido pelo Conselho Nacional de Relações do Trabalho (CNRT) . A representatividade seria conceituada como de natureza comprovada (se atendidos os pré-requisitos dispostos na PEC) ou de natureza derivada (caso as centrais sindicais, confederações e federações do mesmo ramo econômico - e com número de trabalhadores sindicalizados superior ao mínimo necessário para o reconhecimento da representatividade - por ventura

5 Algumas atribuições do CNRT serão abordadas ao longo do texto. 


\section{管ESE}

Revista Eletrônica dos Pós-Graduandos em Sociologia Política da UFSC

Vol. 5. n. 1 (1) agosto-dezembro/2008

ISSN 1806-5023

empregassem o "excedente" dessa representação na criação de novos sindicatos) ${ }^{6}$. Estes novos sindicatos deveriam atrelar-se às centrais, confederações e federações que utilizariam a representação excedente na criação de um ou mais sindicatos.

Algumas regras deveriam ser atendidas de modo a alcançar os critérios de representatividade previstos na PEC. Aos sindicatos, era solicitado comprovar filiação superior a $20 \%$ do total de trabalhadores no âmbito de atuação. Para ocorrer a legalização da central sindical, seria necessário comprovar os seguintes pontos: 1. Sindicatos filiados em 18 estados, no mínimo, dispersos nas 5 regiões do Brasil e em 7 setores econômicos ou 2. Sindicatos filiados em 12 estados, nas 5 regiões do Brasil, com índice percentual de filiação mínimo de 5\% por estado; 3 . Trabalhadores dos sindicatos filiados às centrais em número igual ou superior a $20 \%$ do total de trabalhadores no âmbito da representação sindical; 4. Filiação de trabalhadores em, no mínimo, 5 setores econômicos, com 5\% de trabalhadores no âmbito de representação sindical.

As receitas das entidades sindicais passariam a ser: 1. Contribuição associativa, 2. Contribuição de negociação coletiva, 3. Frutos dos rendimentos de seu patrimônio, 4. Doações e legados, quando aceitos na forma de seus estatutos e multas, dentre outras rendas residuais. A contribuição associativa seria de natureza espontânea, de acordo com deliberações de assembléias futuras. A contribuição de negociação coletiva teria teto estipulado de $1 \%$ da remuneração do ano anterior do trabalhador, pagas em, no mínimo, três parcelas. Estas contribuições seriam rateadas da seguinte forma: 10\% para as centrais sindicais; $5 \%$ para as confederações; $10 \%$ para as federações; $70 \%$ para os

6 Caso da Força Sindical, no Estado de São Paulo, onde esta central goza de grande densidade sindical. Este ponto gerou inúmeras críticas na época, notadamente entre as centrais sindicais menores. 


\section{T⿱⺈ $\mathrm{ESE}$}

Revista Eletrônica dos Pós-Graduandos em Sociologia Política da UFSC

Vol. 5. n. 1 (1) agosto-dezembro/2008

ISSN 1806-5023

sindicatos; 5\% para o Fundo Solidário de Promoção Sindical (FSPS), que custearia as atividades do CNRT.

Os trabalhadores teriam direito à representação no local de trabalho caso o estabelecimento empregatício observasse o número mínimo de 30 trabalhadores. $\mathrm{Na}$ impossibilidade de se alcançar este número, a representação poderia ser criada por intermédio de acordo coletivo. Os representantes eleitos estariam protegidos contra transferência unilateral e indicados, em primeira instância, a negociar com os empregadores. Haveria espaço para negociações coletivas contínuas e renováveis por até 3 anos e a Justiça do Trabalho teria de se limitar às propostas feitas pelas partes envolvidas ${ }^{7}$. Sua utilização só seria demandada caso ocorresse o fracasso dos acordos coletivos destinados à renovação de um contrato coletivo em vigor.

O direito de greve era abordado no texto de forma breve, porém com implicações importantes, principalmente no que diz respeito a sua legitimidade. Para a greve ser considerada legítima, a entidade sindical deveria comunicar com antecedência de 72 horas o início da paralisação e manter o mínimo de pessoas na manutenção de

$7 \mathrm{O}$ direito do trabalho no Brasil sempre primou por ser legislado e não negociado, com as normas vindas de fora do conflito entre capital e trabalho (no caso brasileiro, do Estado). Nos modelos legislados, tanto capital quanto trabalho esperam que as normas sejam cumpridas, sob a pena de que estas normas percam legitimidade. Desta forma, os tribunais tornam-se a arena da "luta de classes" (CARDOSO, 2003, p.148-149). Nos anos 1990, a despeito da estrutura sindical, cresceu em quantidade o número de negociações de base. Nesta situação, os maiores sindicatos, com maior autonomia, têm maior capacidade de negociação, inclusive em relação às federações e confederações. Para Cardoso, o aumento das demandas trabalhistas ocorre devido a crescente deslegitimação do direito do trabalho pelos empregadores. O aumento nada mais é que uma reação ao não cumprimento da ordem legal. "Os capitalistas se sentem, crescentemente, desobrigados, flexibilizando a frio o mercado de trabalho ao cobrilo com o manto negro da ilegalidade. Como o modelo é legislado, o resultado esperado não é outro senão o recurso à Justiça" (CARDOSO, 2003, p. 159-160). No modelo contratual, a quebra da norma legal gera a greve. No modelo legislado, a quebra da norma legal gera o processo na Justiça do Trabalho. Este modelo de legislação, que não é estendida à população em geral, mostra como se dá a exclusão de grande parcela da população do "contrato social" no mundo moderno. A solução seria um Estado estrategistareconciliador que regulasse o processo de individualização. “(...) [N]inguém pode substituir o Estado em sua função fundamental que é comandar a manobra e evitar o naufrágio” (CASTEL, 1999, p.611). 


\section{管ESE}

Revista Eletrônica dos Pós-Graduandos em Sociologia Política da UFSC

Vol. 5. n. 1 (1) agosto-dezembro/2008

ISSN 1806-5023

serviços "essenciais", casos de hospitais, transportes coletivos e telecomunicações, entre outros. O direito de greve dos servidores públicos, contudo, não era passível de regulamentação nesta $\mathrm{PEC}^{8}$.

Por fim, o Conselho Nacional de Relações do Trabalho (CNRT) - de caráter tripartite e paritário - compor-se-ia pelas esferas patronal, sindical e estatal, numa formatação similar ao FNT. As indicações ficariam a cargo do Ministério do Trabalho e Emprego e os membros teriam, dentre outras atribuições, o poder de definir prazos para a comprovação de representatividade dos sindicatos e propor mudanças nas regras que constariam nos estatutos dos sindicatos. Este seria o órgão pelo qual o Estado poderia interferir nos sindicatos e na estrutura sindical como um todo, dando legitimidade para que o sindicato pudesse ser criado.

Nos planos do governo, a PEC 369/05 deveria ser votada ainda em 2005, para posterior discussão da reforma trabalhista, posição defendida à época pelas centrais sindicais. Os empresários, contudo, posicionavam-se contrários, acusando o governo federal de excessiva regulação do processo como um todo. A principal fonte de discórdia e conflito entre governo, entidades sindicais e empresários era o fato da reforma sindical ser tratada pelo governo como prioritária, em detrimento da reforma trabalhista.

Os sindicatos alegavam que o possível fim da unicidade sindical diminuiria a possibilidade de sobrevivência dos sindicatos e centrais sindicais menores. Em contrapartida, as centrais argumentavam que a preocupação maior era com a coesão dos

8 No que concerne ao direito de greve dos servidores públicos, as decisões mais importantes após 2005 foram a diretriz dada, em outubro de 2007, pelo STF em regulamentar, no que couber, o direito de greve do servidor publico de acordo com a lei de greve vigente no setor privado (lei 7783/89), e a vontade do presidente Lula em aprovar a convenção 151 da Organização Internacional do Trabalho (OIT), que trata da organização sindical para servidores públicos (Folha Online, 14/02/2008). 


\section{管ESE}

Revista Eletrônica dos Pós-Graduandos em Sociologia Política da UFSC

Vol. 5. n. 1 (1) agosto-dezembro/2008

ISSN 1806-5023

trabalhadores frente aos empresários. A retirada da norma mais benéfica do texto final do FNT (no caso de haver duas negociações, uma de cúpula e outra na base sindical, ser prioritária a mais benéfica ao trabalhador), era um sinal, no entender das entidades sindicais representantes dos trabalhadores, de que havia espaço para uma reforma trabalhista que retirasse direitos já consagrados.

Da parte dos empresários, havia o receio de que a reforma pudesse fortalecesse politicamente os trabalhadores. A criação do CNRT era vista com desconfiança pela possível influência estatal, já que possibilitaria uma maior interferência, retirada de agilidade nos acordos com os sindicatos e a impossibilidade de se fazer uma reforma trabalhista anterior a reforma sindical (Folha Online, 15/03/2005). Os aspectos positivos resumir-se-iam ao fim da unicidade sindical, estímulo à negociação coletiva e simplificação na resolução dos conflitos.

$\mathrm{Na}$ medida em que as discussões referentes à reforma sindical tornavam-se cada vez mais veementes na Câmara dos Deputados, atores políticos anteriormente colocados à margem da formatação da PEC, começavam a romper com o "consenso" propagado, como era o caso das confederações dos trabalhadores, que defendiam a manutenção da contribuição sindical compulsória, questionando $o$ fato de $\mathrm{o}$ governo buscar "desarticular os sindicatos para que não haja uma oposição consistente à política neoliberal e o achatamento dos salários" (Agência Câmara, 13/04/2005).

Rapidamente, a reforma sindical deixava de ser tratada como prioritária. Verificava-se que a autonomia desejada inicialmente para sindicatos e trabalhadores, que só se efetuaria com o fim da unicidade sindical, da contribuição compulsória e do monopólio da organização, não era possível por não haver bases político-partidárias, sindicais e econômicas devidamente solidificadas nesse intuito. Proteção, naquela conjuntura, significaria tutela e segurança contra um estado de coisas que se direcionava 


\section{管ESE}

Revista Eletrônica dos Pós-Graduandos em Sociologia Política da UFSC

Vol. 5. n. 1 (1) agosto-dezembro/2008

ISSN 1806-5023

a uma diminuição da relevância dos sindicatos. As "inúmeras discussões" não foram capazes de englobar a totalidade dos atores políticos interessados na reforma. Conseqüentemente, o período entre março e julho de 2005 funcionou como uma espécie de " $2^{\circ}$ Fórum Nacional do Trabalho", mais global, ríspido e intransigente, com os principais interessados demonstrando má vontade em ceder nas suas posições iniciais.

No mar de discussões, disputas, hesitações e certezas que colocavam nos holofotes a reforma sindical, diversas coligações surgiram para minar ou apoiar os esforços do governo. Era possível perceber três correntes que, de modo geral, solidificavam-se a ponto de merecerem citação: 1. "corrente governista" - formada por membros do PT e das centrais sindicais; 2. "oposição dos trabalhadores" - formada pela esquerda da Central Única dos Trabalhadores (CUT), partidos de esquerda, tais como o Partido Socialista dos Trabalhadores Unificado (PSTU), Partido Comunista do Brasil (PCdoB) e Partido Socialismo e Liberdade (P-Sol), além de membros da estrutura sindical oficial (sindicatos, federações e confederações de trabalhadores), contrários à reforma por temer que esta fosse implementada para diminuir o poder dos trabalhadores e deixá-los a mercê dos empregadores"; 3. "oposição dos empregadores" - formada por todas as instâncias sindicais representativas dos empregadores, tendo como baluarte a Federação das Industrias do Estado de São Paulo (Fiesp), com exceção de alguns empresários que se mostravam simpáticos à idéia da reforma sindical.

Neste (e em outros micro-cenários verificados) o essencial é extrair uma certa lógica das atitudes verificadas pelos diversos grupos de interesse em disputa. Por mais

9 No dia 28 de junho de 2005, os sindicalistas anti-reformistas, herdeiros diretos dos sindicatos, federações, confederações e centrais sindicais "pelegas", se reuniram em Brasília para unificar os esforços numa central sindical favorável à unicidade sindical, à representação dos trabalhadores por categoria profissional e ao imposto sindical compulsório. A "Nova Central Sindical" reconhecia como positivo, dentre os artigos da PEC, apenas o advento da central sindical reconhecida pelo Ministério do Trabalho, desde que com reconhecida representatividade. 


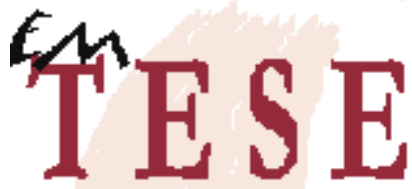

Revista Eletrônica dos Pós-Graduandos em Sociologia Política da UFSC

Vol. 5. n. 1 (1) agosto-dezembro/2008

ISSN 1806-5023

que possamos observar, em determinadas situações, a construção de coalizões momentâneas, faz-se necessário distinguir os movimentos considerados "orgânicos" dos movimentos "ocasionais" (ou conjunturais) presentes no cerne das correlações de forças (Gramsci, 2000, 36-37).

\section{III - ALTERNATIVAS A PEC 369/05}

\section{O "Substitutivo Zimmermann"}

O primeiro sinal de que a PEC não apresentava condições de ser aprovada no Congresso Nacional (caso não houvesse um consenso de fato) foi dado pelo então relator da reforma sindical na Comissão de Trabalho, Administração e Serviço Público, Deputado Federal Tarcísio Zimmermann (PT-RS), através do substitutivo ao Projeto de Lei 1528, de 1989 - conhecido como "Substitutivo Zimmermann" - que se pautava pela observância do texto constitucional vigente, através da regulamentação do artigo $8^{\circ}$ da Constituição Federal de 1988, relativo à organização sindical, planejando alterar também a Consolidação das Leis do Trabalho (CLT), no que diz respeito à negociação coletiva e às convenções coletivas de trabalho. Interessante notar que, mesmo aplacado o teor reformista, coexistiam duas grandes disputas: a dos trabalhadores contra os empregadores, em questões mais gerais concernentes à representatividade nos locais de trabalho, substituição processual e negociação coletiva; e a disputa entre duas coalizões de trabalhadores, colocando em conflito os grupos que, de alguma forma, teriam a ganhar com a aprovação da PEC 369/05 ou do substitutivo (caso das grandes centrais sindicais e grandes sindicatos), e grupos que teriam algo a perder (como os pequenos sindicatos, federações, confederações e centrais sindicais minoritárias). 


\section{T⿱⺈ $\mathrm{TSE}$}

Revista Eletrônica dos Pós-Graduandos em Sociologia Política da UFSC

Vol. 5. n. 1 (1) agosto-dezembro/2008

ISSN 1806-5023

A demora na aprovação de mudanças relativas à esfera sindical, causado em parte pelo impasse entre trabalhadores e empregadores, em parte pela crise política que paralisava o governo no segundo semestre de 2005 repetia-se, com um agravante: enquanto a PEC 369/05 tinha o patrocínio decidido do governo federal, este substitutivo não gozava de qualquer apoio governamental, já que no limiar do processo eleitoral de 2006, tentar aprovar qualquer matéria considerada "polêmica", revelar-se-ia demasiado arriscado.

Pacote de Maio de 2006

No dia 8 de maio de 2006, o presidente Luis Inácio Lula da Silva lançava um pacote de mudanças nas leis sindicais e trabalhistas, através das Medidas Provisórias (MP) 293 e 294 (Agência Brasil, 08/05/2006). Em linhas gerais, as duas MP's eram influenciadas pelo texto concernente a ambas na PEC 369/05, com algumas modificações.

A MP 293 (referente ao reconhecimento das centrais sindicais) apresentava como novidades, além da representação sindical indireta, já que trata da representação "através de instituições sindicais", o teor mais brando na prerrogativa da central ser legítima para representação sindical (cujos requisitos mínimos eram: 1. 100 sindicatos das 5 regiões do Brasil; 2. 20 sindicatos em 3 regiões do Brasil; 3. Filiação sindical em 5 setores de atividade econômica; 4. 10\% do total de empregados sindicalizados em âmbito nacional).

A MP 294 referia-se à criação do Conselho Nacional de Relações do Trabalho, órgão de natureza consultiva e deliberativa, de composição tripartite e paritária, a ser composto por 15 membros titulares e 15 membros suplentes, nas câmaras tripartites, e 


\section{管ESE}

Revista Eletrônica dos Pós-Graduandos em Sociologia Política da UFSC

Vol. 5. n. 1 (1) agosto-dezembro/2008

ISSN 1806-5023

de 5 membros titulares e 5 membros suplentes nas 2 câmaras bipartite (trabalhadoresgoverno e empresários-governo). Os representantes do governo seriam indicados pelos titulares dos órgãos do poder público que integrariam o CNRT; os representantes dos trabalhadores, pelas centrais sindicais representativas (de acordo com a MP 293), e os representantes dos empregadores, pelas confederações registradas no MTE. Caberia ao CNRT normatizar assuntos referentes às relações de trabalho e à organização sindical (funcionamento dos sindicatos, avaliar as proposições no Congresso Nacional relativos ao tema).

Posições políticas relevantes condicionadas ao anúncio do pacote de medidas eram percebidas apenas entre as centrais sindicais (principalmente, CUT e Força Sindical), que almejavam no bojo do seu reconhecimento legal, tão somente conseguir parte do imposto sindical correspondente. Ficava claro que, de um posicionamento favorável à elaboração de formas alternativas para custear a estrutura sindical, as centrais sindicais hegemônicas passavam a enxergar apenas mudanças que as favorecessem. Mais do que isso, também era notória a diminuição do arco de alianças para defender mudanças que: 1. Não contemplavam o conjunto do movimento sindical; 2. Eram feitas de maneira arbitraria (via MP), sem o propalado consenso.

Não obstante, as centrais sindicais nutriam o temor de que as MP's por ventura perdessem sua validade após os 120 dias regulamentares de vigência das mesmas. Entretanto, antes do prazo extinguir-se, uma Ação Direta de Inconstitucionalidade (ADI) no Supremo Tribunal Federal era ajuizada contestando a legalidade (DIAP, 31/07/2006). A ADI apresentada era apoiada pelas confederações de trabalhadores demonstrando que, no interior do movimento sindical, ainda estava acesa a chama da disputa de poder - agora polarizada - entre as centrais sindicais e as confederações. Tais disputas não impediam acordos ocasionais. Porém, os exemplos existentes de coesão, 


\section{管ESE}

Revista Eletrônica dos Pós-Graduandos em Sociologia Política da UFSC

Vol. 5. n. 1 (1) agosto-dezembro/2008

ISSN 1806-5023

além de débeis, eram raros numa atmosfera de disputa por duas concepções antagônicas de estruturação do movimento sindical ${ }^{10}$.

Nos termos da ADI, a legalização das centrais sindicais só poderia ser sacramentada via Emenda à Constituição (DIAP, 31/07/2006). Podemos presenciar, desta maneira, o poder do lobby praticado pelas confederações, federações e sindicatos de trabalhadores, contra a intenção das centrais em se tornarem membros da estrutura sindical oficial (Folha Online, 05/09/2006). Afinal de contas, num primeiro momento, a regulamentação das centrais sindicais prejudicaria as confederações e (em menor grau) as federações de trabalhadores que, como entidades sindicais de $2^{\circ}$ grau, ficariam passíveis de maior inferioridade hierárquica na estrutura sindical, sofrendo sensível redução na participação do imposto sindical. A diminuição da influência dos sindicatos apareceria num $2^{\circ}$ momento, pois, uma vez regulamentada, a central sindical passaria a ser responsável jurídica nas negociações de todos os dissídios coletivos.

De forma quase que previsível, ambas as MP's tiveram sua existência abreviada. Não foram votadas, em grande parte pelo desprezo das lideranças governistas no Congresso e pela cúpula do governo federal, entendendo o quão improcedente era continuar apoiando a matéria naquela conjuntura específica.

\section{PL 1990/07 (PLC 88/07)}

O Projeto de Lei (PL) 1990/07 (no Senado Federal, Projeto de Lei Complementar 88/07), relativo à regulamentação do funcionamento das centrais

10 Um exemplo interessante é a coalizão formada por Força Sindical, CGT (Confederação Geral dos Trabalhadores) e a CNTM (Confederação Nacional dos Trabalhadores Metalúrgicos), pedindo a suspensão da MP que liberava a utilização de R\$ 5 bilhões do FGTS para financiamento do PAC (Programa de Aceleração do Crescimento), rapidamente desfeita assim que a Força Sindical - em união com a CUT - aceitou apoiar a proposta do governo (Folha Online, 23/01/2007 e 12/02/2007). 


\section{管ESE}

Revista Eletrônica dos Pós-Graduandos em Sociologia Política da UFSC

Vol. 5. n. 1 (1) agosto-dezembro/2008

ISSN 1806-5023

sindicais, foi apresentado à Câmara dos Deputados no dia 5 de setembro de 2007. Sua importância devia-se ao fato de ter provocado a maior repercussão dentre as alternativas a PEC 369/05, em grande medida pelo teor do texto, principalmente no que se referia à emenda proposta pelo Deputado Federal Augusto Carvalho (PPS/DF), cuja contribuição sindical só deveria ser depositada na conta do sindicato em caso de aprovação previa do trabalhador para desconto no contracheque. A emenda, aprovada em $1^{\circ}$ turno na Câmara dos Deputados, posteriormente seria rejeitada pelo Senado Federal, na Comissão de Assuntos Sociais (CAS) e na Comissão de Assuntos Econômicos (CAE) (DIAP, $28 / 11 / 2007)^{11}$. Era reafirmado o pensamento de que acabar com o imposto sindical sem transição alguma - se igualaria a ferir de morte o sindicalismo no Brasil.

A manutenção do imposto sindical teve como conseqüência um acordo entre governo e oposição, no intuito de encaminhar projeto de lei a fim de instituir a contribuição negocial, que unificaria o imposto sindical, a contribuição assistencial e a contribuição confederativa (DIAP, 29/01/2008) ${ }^{12}$. Para o Ministro do Trabalho e Emprego, Carlos Lupi, nada mais do que um acordo para fazer a reforma sindical por etapas, ao fechar proposta sobre a legalização das centrais sindicais, imposto sindical e trabalho no comercio aos domingos, dentre outros pontos (Folha Online, 08/11/2007).

A estrutura sindical sofria ataques no seu ponto mais sensível, ou seja, na forma como se daria o seu financiamento. Tentativas de acordo pareciam soar inócuas, uma vez que, enquanto as centrais sindicais se movimentam para evitar as mudanças prejudiciais aos seus interesses (DIAP, 01/02/2008), o governo federal tentava

11 Posteriormente, Augusto Carvalho apresentou esta proposta, agora vinculada ao PL 2424/07, alterando a CLT, para tornar facultada a contribuição sindical.

12 Tal acordo legislaria não apenas sobre a contribuição negocial, como também acerca da criação do Fundo Solidário de Promoção Sindical (FSPS) e do Conselho Nacional de Relações do Trabalho (CNRT). Alias, seria a terceira tentativa de Lula para emplacar tal conselho. Das outras duas vezes, sem sucesso. 


\section{管ESE}

Revista Eletrônica dos Pós-Graduandos em Sociologia Política da UFSC

Vol. 5. n. 1 (1) agosto-dezembro/2008

ISSN 1806-5023

aproximar-se das confederações, no intuito de aprovar a mudança de paradigma na contribuição sindical (DIAP, 06/02/2008).

Uma vez aprovado no Senado Federal, o PL 1990/07 retornaria à Câmara sob um forte lobby das centrais sindicais, que pressionavam os líderes dos principais partidos $^{13}$ para posicionarem-se favoráveis ao seu reconhecimento formal, excluindo a emenda de Augusto Carvalho (DIAP, 06/03/2008). O Projeto de Lei seria ratificado no dia 31 de março de 2008 pelo presidente Lula (Lei No . 11.648), com veto presidencial ao artigo $6^{\circ}$, concernente a fiscalização dos valores recebidos pelas centrais sindicais, alusivos ao imposto sindical, pelo Tribunal de Contas da União (TCU) (Folha Online, 01/04/2008), sob o pretexto de que tal artigo poderia interferir na organização e autonomia das entidades sindicais ${ }^{14}$.

São estes os pontos principais sobre os quais a Lei 11.648 se debruça: I Prerrogativas da central sindical (coordenar a representação dos trabalhadores por meio das organizações sindicais a ela filiadas; participar de negociações em fóruns, colegiados de órgãos públicos e demais espaços de diálogo social que possuam composição tripartite, nos quais estejam em discussão assuntos de interesse geral dos trabalhadores); II - Critérios para a legalização da central sindical, pelo Ministério do Trabalho e Emprego (1 - filiação de, no mínimo, 100 (cem) sindicatos distribuídos nas 5 (cinco) regiões do País; 2 - filiação em pelo menos 3 (três) regiões do País de, no mínimo, 20 (vinte) sindicatos em cada uma; 3 - filiação de sindicatos em, no mínimo, 5 (cinco)

13 Como demonstração inequívoca de gratidão, as centrais sindicais organizaram um coquetel em homenagem aos Deputados que votaram a favor de sua regularização jurídica (Folha Online, 10/04/2008). 14 O DEM foi o único partido da base oposicionista a se manifestar de forma mais veemente, através de uma Ação Direta de Inconstitucionalidade (ADI) no STF, questionando o veto do presidente Luiz Inácio Lula da Silva ao artigo $6^{\circ}$, aprovado pela Câmara dos Deputados. A alegação do partido concentrava-se no fato de que, segundo o artigo $8^{\circ}$ da Constituição Federal, os sindicatos eram os legítimos representantes dos trabalhadores nas categorias profissionais, ficando fora de cogitação, portanto, a atuação das centrais sindicais como representantes dos trabalhadores (DIAP, 14/04/2008). 


\section{管ESE}

Revista Eletrônica dos Pós-Graduandos em Sociologia Política da UFSC

Vol. 5. n. 1 (1) agosto-dezembro/2008

ISSN 1806-5023

setores de atividade econômica; e 4 - filiação de sindicatos que representem, no mínimo, $7 \%$ (sete por cento) do total de empregados sindicalizados em âmbito nacional (5\% nos primeiros 24 meses após a publicação da Lei)); III - Indicação das centrais para participar nos fóruns tripartites, conselhos e colegiados de órgãos públicos (proporcional à representatividade das centrais, salvo acordo entre as mesmas, sem prejudicar quaisquer centrais e preservando a paridade da representação dos trabalhadores e empresários nos órgãos em que as centrais sindicais participam como representantes dos trabalhadores); IV - Divisão dos recursos das entidades sindicais representantes dos trabalhadores (60\% aos sindicatos, $15 \%$ para as federações; $5 \%$ para as confederações; $10 \%$ para as centrais sindicais e 10\% para o Ministério do Trabalho e Emprego - através da "Conta Especial Emprego e Salário"). O sindicato necessitaria indicar ao Ministério apenas a central sindical a qual estiver filiado, como beneficiária da contribuição sindical ${ }^{15}$. Tornaria-se desnecessário a indicação de federações ou confederações para aporte dos recursos provenientes do imposto sindical. Na impossibilidade de serem contemplados sindicatos ou outras entidades de grau superior, representando determinado grupo de trabalhadores, os recursos do imposto sindical passariam automaticamente ao Ministério do Trabalho e Emprego (MTE).

\section{IV - CONCLUSÃO}

No mês de março de 2008, completaram-se 3 anos desde que a PEC 369/05 havia sido enviada ao Congresso Nacional, pelo então ministro do Trabalho e Emprego, Ricardo Berzoini. Outrossim, o rumo tomado pela reforma sindical (ou pelas micro-

15 Posteriormente, confederações e federações conseguiram (mediante ação judicial) estender a obrigatoriedade do repasse de recursos provenientes dos sindicatos para todos os entes sindicais (e não apenas às centrais, como descrito na Lei). 


\section{管ESE}

Revista Eletrônica dos Pós-Graduandos em Sociologia Política da UFSC

Vol. 5. n. 1 (1) agosto-dezembro/2008

ISSN 1806-5023

reformas) no governo Lula mostrou-se demasiado nebuloso, em grande parte causado pelo emaranhado de disputas intra e intersindicais, sinalizando que sua aprovação necessitava muito mais do que a tão propalada "vontade política".

Cabe então a pergunta: as disputas por hegemonia na esfera institucional não foram sequer previstas pelo governo Lula? Se verificarmos o discurso presente na intelligentzia petista e os caminhos traçados, provavelmente sim. Entretanto, a via do consenso, dirigido pelo governo, demonstrou-se fracassada num curtíssimo espaço de tempo.

O "refugo" da PEC 369/05 tem muito a ver com a formatação do FNT, cujos integrantes, selecionados pelo governo, não contemplavam parcela realmente representativa do movimento sindical dos trabalhadores - e, por que não dizer, dos círculos empresariais - excluindo setores do sindicalismo "oficial" e da base sindical, ao priorizar as centrais sindicais como interlocutores proeminentes. A escolha (pensada ou não) pelo governo Lula de quadros alinhados as suas propostas entre o empresariado e (em maior grau) entre os sindicalistas, contribuindo para a exclusão de quadros importantes nas deliberações no FNT, talvez tenha sido, numa observação retrospectiva, o "pecado original" da reforma sindical.

O conceito de reforma sindical desejada pelo governo Lula trazia em si a idéia de controle, travestido como "consenso", cujos principais aliados eram CUT e Força Sindical. Tal arranjo poderia ser considerado uma "convergência tácita de interesses", em que as centrais sindicais, com a possibilidade de se tornarem representantes - não só políticos, como legais - dos trabalhadores, apoiariam uma maior intervenção estatal, que não se traduziria em mudanças relevantes nas parcelas inferiores da estrutura sindical. A postura do governo, pautada na busca do consenso, devia-se ao fato de que 


\section{管ESE}

Revista Eletrônica dos Pós-Graduandos em Sociologia Política da UFSC

Vol. 5. n. 1 (1) agosto-dezembro/2008

ISSN 1806-5023

os ambientes sindical e empresarial encontravam-se titubeantes graças à possibilidade de mudanças profundas na estrutura sindical.

A "reunião de cúpula" que gerou a proposta de reforma sindical trouxe mais problemas do que soluções, visto que as confederações e federações de trabalhadores perderiam muito espaço para as centrais sindicais, segundo o texto proposto pela PEC; os sindicatos, na prática, não teriam mais poder decisório, servindo apenas para referendar decisões já tomadas pelas centrais sindicais; e os empregadores ver-se-iam hesitantes ao que poderia representar uma maior organização no local de trabalho, ou a qualquer sinalização do governo nesta direção. A paulatina cooptação das centrais sindicais, que aparentemente poderia se configurar num desempate da correlação tripartite de forças favoravelmente ao governo federal, contribuiu para que se construísse um "empate" entre os atores políticos contrários e favoráveis à reforma sindical.

Se o governo federal almejava, com o apoio das centrais sindicais alcançar, num segundo momento, o apoio do movimento sindical dos trabalhadores, conseguiu na verdade apenas exasperar, extravasar a divisão presente entre, de um lado, centrais sindicais e, de outro lado, sindicatos (notadamente, os pequenos), confederações e federações, irremediavelmente contrários à reforma. Talvez o símbolo dessa dicotomia seja a criação da Nova Central Sindical dos Trabalhadores (NCST), criada principalmente - para combater qualquer transformação relevante na estrutura sindical.

As partes que se consideram prejudicadas pela aliança entre Estado e centrais sindicais, os empresários (que discordavam de uma maior interferência estatal nas relações entre capital e trabalho, e da possibilidade de maior influência e poder dos trabalhadores no ambiente de trabalho) e os membros da estrutura sindical oficial (contrários a um maior poder dado às centrais sindicais, inclusive de negociação 


\section{管ESE}

Revista Eletrônica dos Pós-Graduandos em Sociologia Política da UFSC

Vol. 5. n. 1 (1) agosto-dezembro/2008

ISSN 1806-5023

coletiva) posicionavam-se de maneira crítica às mudanças. Em vários momentos, unindo-se (de maneira implícita) para minar qualquer tipo de reforma.

Nem mesmo as tentativas de retirar a reforma do "limbo" (utilizando o ministério do Trabalho como "moeda de troca"16) evitaram que se tornasse hegemônico, ainda no ano de 2005, o pensamento de que a PEC 369/05 não teria a mínima condição de ser aprovada, pela falta de consenso entre os envolvidos. Em verdade, era notório o naufrágio do governo Lula no que concerne à intransigência ao propor uma reforma sindical de cúpula, exatamente pela dificuldade de se reformar a estrutura sindical, sem que interesses enraizados fossem enfrentados, rompidos e soçobrados ${ }^{17}$. Paulatinamente, então, a reforma perdia vigor, condenada que estava ao arquivamento, ou a ser aprovada com uma série de emendas, de modo a desfigurar o texto. Grande parte das tentativas de modificação (ou "aperfeiçoamento", para citar um dos muitos eufemismos usados ao tratar do tema) da estrutura sindical, tinha como ponto convergente manter a unicidade sindical e o imposto sindical, pontos que, segundo a PEC 369/05, deveriam sofrer transformações substanciais.

A reforma sindical do Governo Lula caracterizou-se pela ilusão estatal de poder ser capaz de controlar e conceber pactos e acordos sem que se fossem realmente levadas em consideração as opiniões dos envolvidos. Talvez esse tenha se notabilizado como maior empecilho a qualquer tipo de modificação das normas não tiveram como fim o consenso e não alcançaram o êxito esperado, uma vez que, para além de um consenso e

16 Por exemplo, na indicação de Luis Marinho (então presidente da CUT). Marinho, enquanto ministro, demonstrou vontade em dialogar com a NCST. O fracasso desse dialogo, suponho, contribuiu para a escolha de Carlos Lupi (defensor da estrutura sindical "varguista" e alinhado às confederações) como sucessor no Ministério do Trabalho e Emprego.

17 A tentativa mais recente de levar a cabo mudanças nas esferas sindical e trabalhista foi divulgada no dia 17 de setembro de 2008, tendo como principal articulador o ministro de Assuntos Estratégicos, Mangabeira Unger. Contudo, os mesmos empecilhos das outras tentativas de modificação na estrutura sindical surgiram. 


\section{TिESE}

Revista Eletrônica dos Pós-Graduandos em Sociologia Política da UFSC

Vol. 5. n. 1 (1) agosto-dezembro/2008

ISSN 1806-5023

busca por formatar uma "republica sindical", o desenrolar dos acontecimentos mostrou a construção de uma "aristocracia sindical" dentro do governo federal e uma reestruturação débil da estrutura sindical, incluindo as centrais sindicais na divisão da volumosa quantia proveniente do imposto sindical ${ }^{18}$. A recém-inclusão das centrais sindicais nesta estrutura, longe de apontar para transformações de fato na estrutura sindical, facilita de forma indiscutível sua manutenção ${ }^{19}$.

\section{V - REFERÊNCIAS BIBLIOGRÁFICAS}

\section{Textos / artigos eletrônicos}

CARDOSO, Adalberto Moreira. A década neoliberal e a crise dos sindicatos no Brasil. São Paulo: Boitempo Editorial, 2003.

CASTEL, Robert. As metamorfoses da questão social: uma crônica do salário. Petrópolis: Editora Vozes, 1999.

GRAMSCI, Antonio. Cadernos do cárcere: Vol. 3. Rio de Janeiro: Editora Civilização Brasileira, 2000.

18 No total, as centrais sindicais receberão do Ministério do Trabalho e Emprego, até o final de 2008, cerca de $\mathrm{R} \$ 55,5$ milhões, a serem divididos entre as 6 centrais que atenderam os requisitos dispostos na Lei 11.648. São elas: Central Única dos Trabalhadores (CUT) (R\$ 19,8 milhões), Força Sindical (R\$ 15,1 milhões), União Geral dos Trabalhadores (UGT) (R\$ 8,8 milhões), Nova Central Sindical dos Trabalhadores (NCST) (R\$ 6,6 milhões), Central dos Trabalhadores e Trabalhadoras do Brasil (CTB) (R\$ 2,9 milhões), Central Geral dos Trabalhadores no Brasil (CGTB) (R\$ 2,4 milhões) - Ver Diap, 06/08/2008. Esse valor pode chegar nos próximos anos a R\$ 100 milhões, pois está atrelado a quantidade de sindicatos filiados. Como muitos sindicatos não são filiados a nenhuma central sindical, a disputa promete ser árdua (Folha Online, 02/05/2008).

$19 \mathrm{O}$ anteprojeto de lei referente à Contribuição Negocial (contrapartida para que as centrais sindicais fossem incluídas na estrutura sindical oficial), colocada em discussão pelo Ministério do Trabalho e Emprego, sofreu duras críticas entre as 6 centrais sindicais que receberão verbas provenientes do imposto sindical. A alegação do caráter prejudicial nova contribuição denota a vontade, ao menos no curto prazo, de se manter a contribuição sindical tal como observamos na legislação sindical vigente. 


\section{T⿱⺈ $\mathrm{TSE}$}

Revista Eletrônica dos Pós-Graduandos em Sociologia Política da UFSC

Vol. 5. n. 1 (1) agosto-dezembro/2008

ISSN 1806-5023

MINISTÉRIO DO TRABALHO E EMPREGO, Proposta de Emenda à Constituição:

Projeto de Lei das Relações Sindicais. Brasília, 2005.

PRESIDÊNCIA DA REPUBLICA FEDERATIVA DO BRASIL. Medida Provisória $N^{o}$ 293, de 8 de maio de $2006 . \quad$ In: http://www.planalto.gov.br/ccivil 03/Ato2004-2006/2006/Mpv/293.htm. Presidência da Republica. Casa Civil, Subchefia para Assuntos Jurídicos. Acesso em: 25/04/2008. . Medida Provisória $N^{o}$

294, de 8 de maio de $2006 . \quad$ In:
http://www.planalto.gov.br/ccivil_03/Ato2004-2006/2006/Mpv/294.htm. Presidência da Republica. Casa Civil, Subchefia para Assuntos Jurídicos. Acesso em: 25/04/2008. . Lei No 11648, de 31

de março de $2008 . \quad$ In:

http://www.planalto.gov.br/ccivil 03/ Ato2007-2010/2008/Lei/L11648.htm Presidência da Republica. Casa Civil, Subchefia para Assuntos Jurídicos. Acesso em: 25/04/2008.

RADERMACHER, Reiner \& MELLEIRO, Waldeli. Mudanças no Cenário Sindical Brasileiro sob o Governo de Lula. Nueva Sociedade, № 211, Set-Out 2007. Disponível em: http://www.nuso.org/upload/articulos/3461_2.pdf. Acesso em: 01/05/2008.

ZIMMERMANN, Tarcísio. Substitutivo ao Projeto de Lei no 1528, de 1989. In: http:// www.diap.org.br/agencia/anexos/RefSindPL1528 890rganizaSindNovoSubstitutivoZi mmermann.doc. Acesso em: 20/12/2005.

\section{Noticiário em geral (por ordem cronológica)}




\section{留ESE}

Revista Eletrônica dos Pós-Graduandos em Sociologia Política da UFSC

Vol. 5. n. 1 (1) agosto-dezembro/2008

ISSN 1806-5023

FOLHA ONLINE, 24/11/2002 - Reformas põem centrais sindicais em pé de guerra. In:

http://www1.folha.uol.com.br/folha/dinheiro/ult91u59559.shtml. Acesso em: $01 / 05 / 2008$.

, 02/06/2004 - Reforma provoca disputa por filiação entre centrais sindicais. In: http://www1.folha.uol.com.br/folha/dinheiro/ult91u85069.shtml. Acesso em: 01/05/2008.

, 15/03/2005 - Indústria quer barrar reforma sindical no Congresso.

In: $\quad$ http://www1.folha.uol.com.br/folha/dinheiro/ult91u94393.shtml. Acesso em: $01 / 05 / 2008$.

AGÊNCIA CÂMARA, 13/04/2005 - Trabalho quer votar projeto alternativo à reforma sindical. In:

$\underline{\text { http://www.camara.gov.br/internet/agencia/materias.asp?pk=64483\&pesq }=\text { reforma }}$ \%20sindical. Acesso em: 01/05/2008.

AGENCIA BRASIL, 08/05/2006 - Lula anuncia medidas na área trabalhista. In: http:// www.radiobras.gov.br/materia.phtml?materia=264048\&editoria=PO. Acesso em: 01/05/2008.

DIAP, 31/07/2006 - Confederações ajuízam ação no STF contra o pacote trabalhista do governo. In: http://diap.ps5.com.br/content,0,1,75417,0,0.html. Acesso em: 01/05/2008. FOLHA ONLINE, 05/09/2006 - Câmara aprova de uma só vez 20 medidas provisórias em votações simbólicas. In: http://www1.folha.uol.com.br/folha/brasil/ult96u82550.shtml. Acesso em: 01/05/2008. , 23/01/2007 - Centrais sindicais recorrem ao Supremo contra MP do FGTS. In: http://www1.folha.uol.com.br/folha/dinheiro/ult91u113947.shtml. Acesso em: 01/05/2008. 


\section{留ESE}

Revista Eletrônica dos Pós-Graduandos em Sociologia Política da UFSC

Vol. 5. n. 1 (1) agosto-dezembro/2008

ISSN 1806-5023

, 12/02/2007 - Governo não irá esperar centrais sindicais para criar

fundo com FGTS, diz Marinho. In:

http://www1.folha.uol.com.br/folha/dinheiro/ult91u114449.shtml. Acesso em:

$01 / 05 / 2008$.

, 08/11/2007 - Governo e centrais decidem retomar debate de imposto

In: www.folha.com.br. Acesso em: 01/05/2008.

DIAP, 28/11/2007 - Comissões votam hoje no senado projeto das centrais sindicais. In: http://www.diap.org.br. Acesso em: 01/05/2008.

, 29/01/2008 - Projeto de contribuição negocial em fase avançada de elaboração.

In: http://diap.ps5.com.br/content,0,1,79987,0,0.html. Acesso em: 01/05/2008.

, 01/02/2008 - Centrais sindicais não aceitam propostas do governo. In: http://www.diap.org.br. Acesso em: 01/05/2008.

, 06/02/2008 - Confederações farão parte do Grupo de Trabalho do MTE que discute mudanças na contribuição sindical.

In:http://diap.ps5.com.br/content,0,1,80018,0,0.html. Acesso em: 01/05/2008.

FOLHA ONLINE, 14/02/2008 - Lula diz que governo vai trabalhar para aprovar convenções da $\quad$ OIT. In:

http://www1.folha.uol.com.br/folha/dinheiro/ult91u372395.shtml. Acesso em: 01/05/2008.

DIAP, 06/03/2008 - Centrais pedem apoio aos deputados para votar o PL 1.990/07. In: http://diap.ps5.com.br/content,0,1,80330,0,0.html. Acesso em: 01/05/2008.

FOLHA ONLINE, 01/04/2008 - Lula veta artigo de lei que determinava que TCU iria fiscalizar centrais sindicais. In:

http://www1.folha.uol.com.br/folha/brasil/ult96u387990.shtml. Acesso em: 01/05/2008. 


\section{留ESE}

Revista Eletrônica dos Pós-Graduandos em Sociologia Política da UFSC

Vol. 5. n. 1 (1) agosto-dezembro/2008

ISSN 1806-5023

, 10/04/2008 - Centrais sindicais comemoram com coquetel no

Congresso aprovação de projeto. In:

http://www1.folha.uol.com.br/folha/brasil/ult96u390734.shtml. Acesso em: 01/05/2008.

DIAP, 14/04/2008 - DEM vai ao Supremo contra repasse da contribuição sindical às centrais. In: http://diap.ps5.com.br/content,0,1,80802,0,0.html. Acesso em: 01/05/2008.

FOLHA ONLINE, 02/05/2008 - Governo estima que repasse do imposto sindical será de R\$ 60 milhões. In: http://www1.folha.uol.com.br/folha/dinheiro/ult91u397843.shtml. Acesso em: 05/05/2008.

DIAP, 06/08/2008 - Centrais sindicais: ministro do Trabalho anuncia entidades legalizadas. In : http://diap.ps5.com.br/content, $0,1,82436,0,0 . \mathrm{html}$. Acesso em: 01/05/2008.

, 14/08/2008 - Centrais sindicais não querem fim do imposto sindical agora. In: http://diap.ps5.com.br/content,0,1,82538,0,0.html. Acesso em: 20/10/2008.

, 16/09/2008 - Sindicato de base é obrigado a repassar contribuição sindical. In: http://diap.ps5.com.br/content,0,1,82988,0,0.html. Acesso em: 20/10/2008.

, 19/09/2008 - Posições de Unger sobre reformas sindical e trabalhista causam controvérsias. In: http://diap.ps5.com.br/content, $0,1,83070,0,0 . \mathrm{html}$. Acesso em: 20/10/2008. 